\title{
An innovative approach to develop microporous activated carbons in oxidising atmosphere
}

\author{
Suhas $^{\text {a, * }}$, P.J.M. Carrott ${ }^{\text {b }}$, M.M.L. Ribeiro Carrott ${ }^{\text {b }}$, Randhir Singh a, L.P. Singh ${ }^{\text {, }}$, \\ Monika Chaudhary ${ }^{\mathrm{a}}$ \\ ${ }^{a}$ Department of Chemistry, Gurukula Kangri Vishwavidyalaya, Haridwar, 249404, India \\ b Centro de Química de Évora and Departamento de Química, Universidade de Évora, Colégio Luís António Verney, 7000-671, Évora, Portugal

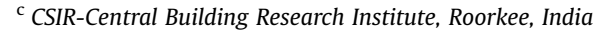

\section{A R T I C L E I N F O}

\section{Article history:}

Received 25 September 2016

Received in revised form 25 March 2017

Accepted 12 April 2017

Available online 14 April 2017

\section{Keywords:}

Air activation

Demineralised kraft lignin

Kraft lignin

Microporous activated carbon

\begin{abstract}
A B S T R A C T
The aim of the study was to investigate a rather oxidising atmosphere such as air for the development of a microporous activated carbon from demineralised kraft lignin. Demineralisation of lignin makes the precursor low in reactivity and hence can allow the use of more oxidising atmospheres. Control of the activation conditions allowed development of microporous activated carbons with type I $\mathrm{N}_{2}$ adsorption isotherms from demineralised kraft lignin having micropore volumes and mean micropore widths up to $0.374 \mathrm{~cm}^{3} \mathrm{~g}^{-1}$ and $1.12 \mathrm{~nm}$, respectively. A unique feature of this study is to prepare high surface area $\left(1305 \mathrm{~m}^{2} \mathrm{~g}^{-1}\right)$ microporous activated carbon at a high temperature $\left(950^{\circ} \mathrm{C}\right)$ in air atmosphere. The effect of temperature on the surface area, micropore volume, mean micropore width and total pore volume was also studied for the development of activated carbons from the precursor in the range $550-1050{ }^{\circ} \mathrm{C}$.
\end{abstract}

() 2017 Elsevier Ltd. All rights reserved.

\section{Introduction}

Activated carbons are high surface area and porous materials with a large adsorption capacity which are widely used as commercial adsorbents. Tailored activated carbons with desirable pore size viz. microporous ( $<2 \mathrm{~nm}$ ), mesoporous $(2-50 \mathrm{~nm})$ or macroporous $(>50 \mathrm{~nm}$ ) can be developed by controlling the preparation process for desired applications. Selection of raw material, activation conditions like activation method, activating agent and time are important parameters which affect the physical and chemical nature of the resultant carbon (Ruiz-Fernandez et al., 2011; Sych et al., 2012), including their surface area and porosity. Among carbons produced generally an ideal activated carbon is one which has high adsorption capacity coupled with pore size as well as surface chemistry optimized for the specific application.

Activated carbons are generally prepared by either of two methods: physical and chemical activation. Physical activation has an advantage over chemical activation because it avoids the incorporation of additives/impurities coming from activating agents (Benaddi et al., 1998). It is normally a two-step process,

\footnotetext{
* Corresponding author.

E-mail address: suhasnatyan@yahoo.com (Suhas).
}

involving carbonization followed by activation in steam, air, carbon dioxide or their mixtures. However, sometimes only the second step is carried out. The cost (Abbaszadeh et al., 2016; Kumar and Jena, 2016) of precursors and energy associated with activated carbon production usually makes them expensive. In order to minimize the cost, alternative low cost precursors or waste materials and less expensive methodologies are being explored by researchers. Air activation is among the methods which is economically attractive owing to the advantages of being free, having low heat requirements and less processing time (Ceyhan et al., 2013; Cho et al., 2014).

A less expensive activated carbon may be prepared by utilizing lignin as a precursor which has wide availability and high carbon content. This material has gained wide interest for the removal of pollutants as such or in the form of activated carbons. A number of studies dealing with its use as natural adsorbent or as an activated carbon has already been published and reviewed (Betancur et al., 2009; Carrott et al., 2010; Cotoruelo et al., 2012; Fierro et al., 2006; Shou and Qiu, 2016; Suhas et al., 2007). Lignin obtained by different methods of isolation with varying physical/chemical contents have been studied as precursors for activated carbons. Interestingly, the precise properties of the activated carbons obtained depend on, besides other parameters, the inorganic impurities (ash) too (Fierro et al., 2007b; Suhas et al., 2009). Lignin, in 
particular kraft lignin prepared from black liquor, a waste material from the paper and pulp industry, is impure and has high ash content (Fierro et al., 2007a; Rodriguez-Mirasol et al., 1993). The impurities sometimes affect the reactivity of the precursors in the activation process.

Research on the feasible utilization of kraft lignin as an activated carbon precursor by physical activation shows that the carbons so prepared by using steam or $\mathrm{CO}_{2}$ generally have surface area in the range 600-1900 $\mathrm{m}^{2} \mathrm{~g}^{-1}$ (Carrott et al., 2008b; Rodriguez-Mirasol et al., 1993; Rosas et al., 2014). The low surface areas with higher burn off usually observed for raw kraft lignin samples (Carrott et al., 2008b; Suhas et al., 2009) compared to the purer lignins (having less ash content/impurities) have been associated to their higher reactivity which in turn is due to their higher ash/mineral content. Interestingly, since demineralised lignins are less reactive (Fierro et al., 2007b; Suhas et al., 2009) it may therefore be possible to utilize preferentially some oxidising agents like air for production of activated carbons. To the best of our knowledge, in spite of its potential use, there have not been studies reporting the preparation of AC from demineralised lignin at high temperatures using physical activation in air. Despite the economic benefits of using air as the activating agent, air activation is not commonly used because of the high reactivity of oxygen, which makes it difficult to control excessive carbon burn off (Cho et al., 2014). Demineralised kraft lignin being less reactive in nature may be used as a precursor for air activation. In this work, it is shown that under proper conditions of physical activation in air, it is possible to prepare microporous activated carbons with high surface areas from demineralised kraft lignin which have characteristics comparable to those of the activated carbons prepared from even more costly precursors.

\section{Experimental}

\subsection{Materials and methods}

The raw kraft lignin sample was procured from Lignotech Iberica and is similar to that of previous work (Suhas et al., 2009). The demineralisation process for the removal of inorganic impurities/ mineral content was carried out according to the procedure discussed elsewhere (Suhas et al., 2009). The sample so produced was dried and stored in sample flasks for further use.

For the preparation of activated carbons in air approximately $5 \mathrm{~g}$ of the demineralised kraft lignin was placed in a ceramic crucible and positioned in the central constant temperature zone of a conventional muffle furnace. The activation process was implemented by heating the sample to the desired temperature $\left(550-1050{ }^{\circ} \mathrm{C}\right)$ at a rate of $8{ }^{\circ} \mathrm{C} \mathrm{min}{ }^{-1}$ under air atmosphere and maintaining for $30 \mathrm{~min}$. The sample so prepared was cooled to room temperature and stored in airtight containers and was put in desiccators for further use. A comparison has been made between some results of activated carbons prepared from demineralised lignin and the commercial activated carbon procured from Rankem (India).

\subsection{Characterization of adsorbents}

The humidity and ash content were analysed according to ASTM and ISO standard methods (ASTM, 2004a, b; ISO, 1997, 2003). Elemental analysis was performed using a EuroVector CHNS analyser and each analysis was the result of at least 3 replicate determinations. X-ray diffraction (XRD) measurements were carried out on a Bruker AXS-D8 Advance powder diffractometer, using Cu $\mathrm{K} \alpha$ radiation $(40 \mathrm{kV}, 30 \mathrm{~mA})$, with a step size of $0.02^{\circ}(2 \theta)$ and $4 \mathrm{~s}$ per step. The Fourier Transform Infrared (FTIR) spectroscopic studies of the samples were carried out using a Perkin Elmer model Paragon 1000 PC spectrophotometer. For this the dried samples were mixed with dry $\mathrm{KBr}$ with a ratio of about 1:450 and then ground to very fine powder. About $170 \mathrm{mg}$ of fine powder was then used to make a self-supporting disc. The morphology of the samples was observed using field emission scanning electron microscopy (FE-SEM, Tescan Mira 3).

The porous properties and surface area were analysed by means of nitrogen adsorption at $77 \mathrm{~K}$. The $\mathrm{N}_{2}$ adsorption-desorption isotherms of commercial activated carbon and activated carbons prepared from raw kraft lignin, hydrolytic lignin and demineralised kraft lignin were determined at $77 \mathrm{~K}$ using Micromeritics ASAP 2010 and Quantachrome Quadrasorb 3SI, using helium (for dead space calibration) and nitrogen of $99.999 \%$ purity supplied respectively, by Linde and Air Liquide. Prior to the adsorption measurements all samples were outgassed for $4 \mathrm{~h}$ at $300{ }^{\circ} \mathrm{C}$. The $\mathrm{N}_{2}$ isotherms were analysed by means of Brunauer-Emmett-Teller (BET) model for surface area measurement and the $\alpha_{\mathrm{s}}$ method using published standard data in order to obtain the total pore volume $v_{s}$ (Carrott et al., 1991). They were also analysed by means of the DR equation in order to obtain the DR pore volume, $v_{0}$, and the corresponding estimate of apparent mean pore width, $\mathrm{L}_{0}$, from the relationship:

$\mathrm{L}_{\mathrm{o}}=10.8 /\left(\mathrm{E}_{\mathrm{o}}-11.4\right)$

where $E_{o}$ is the characteristic energy obtained by application of the DR Equation. The liquid density of $\mathrm{N}_{2}$ was taken as $0.808 \mathrm{~g} \mathrm{~cm}^{-3}$ and the affinity coefficient as $\beta=0.34$.

\section{Results and discussion}

Proximate analysis (according to ISO and ASTM standards) and CHNS elemental analysis of demineralised kraft lignin was carried out and presented in Table 1. A comparison of the results with raw kraft lignin shows that the demineralised kraft lignin has relatively high carbon content as compared to raw kraft lignin which suggests that it should be a better precursor for the preparation of activated carbons. The demineralisation of lignin also caused a decrease in sulfur content. The humidity and ash content (Table 1) in the demineralised kraft lignin becomes low after acid treatment. The humidity content lowered from 11.8 to $4.8 \%$ whereas the ash content was reduced from 15.4 to $0.1 \%$ (ISO standard), which was quite similar to the results observed by Serrano et al. (Gonzalez-Serrano et al., 2004). The low humidity and ash contents make demineralised kraft lignin a relatively pure material to be used as precursor for the preparation of activated carbon. The nature of the impurities present in raw kraft lignin has been discussed by Carrott et al (2008b) and confirmed the presence of impurities such as $\mathrm{Na}$ (6.19\%), Ca (0.13\%), $\mathrm{Al}(0.04 \%)$ and $\mathrm{Mg}(0.01 \%)$.

Representative X-ray diffraction patterns, for the raw kraft lignin, demineralised kraft lignin and activated carbons prepared from demineralised kraft lignin at different temperatures in air are shown in Fig. 1. The XRD pattern (Fig. 1a) of raw kraft lignin shows some peaks which are due to the presence of inorganic impurities and are discussed elsewhere (Carrott et al., 2008b) and the ash analysis confirmed the presence of sodium carbonate sulfate in the sample. Interestingly, these peaks do not appear in the XRD pattern of the lignin sample after acid treatment, which is in good agreement with the ash content discussed in the preceding paragraphs and further confirms our view that the sample is quite low in inorganic impurities and is demineralised now.

Further, the XRD pattern of all activated carbons prepared from demineralised kraft lignin at various temperatures showed a diffuse pattern and indicated its amorphous nature. Figure 1(b) shows the typical XRD pattern of the representative activated carbons prepared at 750,850 and $950{ }^{\circ} \mathrm{C}$ temperatures. Two broad 
Table 1

Humidity, ash content and elemental analysis of lignin samples.

\begin{tabular}{|c|c|c|c|c|c|c|c|c|}
\hline \multirow[t]{2}{*}{ Sample } & \multicolumn{2}{|l|}{ Humidity/\% } & \multicolumn{2}{|l|}{ Ash/\% } & \multicolumn{4}{|c|}{ Elemental analysis/\% } \\
\hline & $\begin{array}{l}\text { ASTM } \\
\text { D2867-04 } \\
145^{\circ} \mathrm{C}\end{array}$ & $\begin{array}{l}\text { ISO } \\
589^{\mathrm{b}} \\
110^{\circ} \mathrm{C}\end{array}$ & $\begin{array}{l}\text { ASTM } \\
\text { D2866-94 } \\
650{ }^{\circ} \mathrm{C}\end{array}$ & $\begin{array}{l}\text { ISO } \\
1171^{\mathrm{d}} \\
815^{\circ} \mathrm{C}\end{array}$ & $\mathrm{C}$ & $\mathrm{H}$ & $\mathrm{N}$ & $\mathrm{S}$ \\
\hline Raw kraft lignin ${ }^{e}$ & 13.8 & 11.8 & 20.8 & 15.4 & 52.7 & 4.7 & 0.2 & 1.2 \\
\hline Demineralised kraft lignin & 6.0 & 4.8 & 0.3 & 0.1 & 63.9 & 4.9 & 0.1 & 0.4 \\
\hline $\begin{array}{l}\text { a }(\text { ASTM, 2004b). } \\
\text { b }(\text { ISO, 2003). } \\
\text { c (ASTM, 2004a). } \\
\text { d (ISO, 1997). } \\
\text { e (Carrott et al., 2008b). }\end{array}$ & & & & & & & & \\
\hline
\end{tabular}
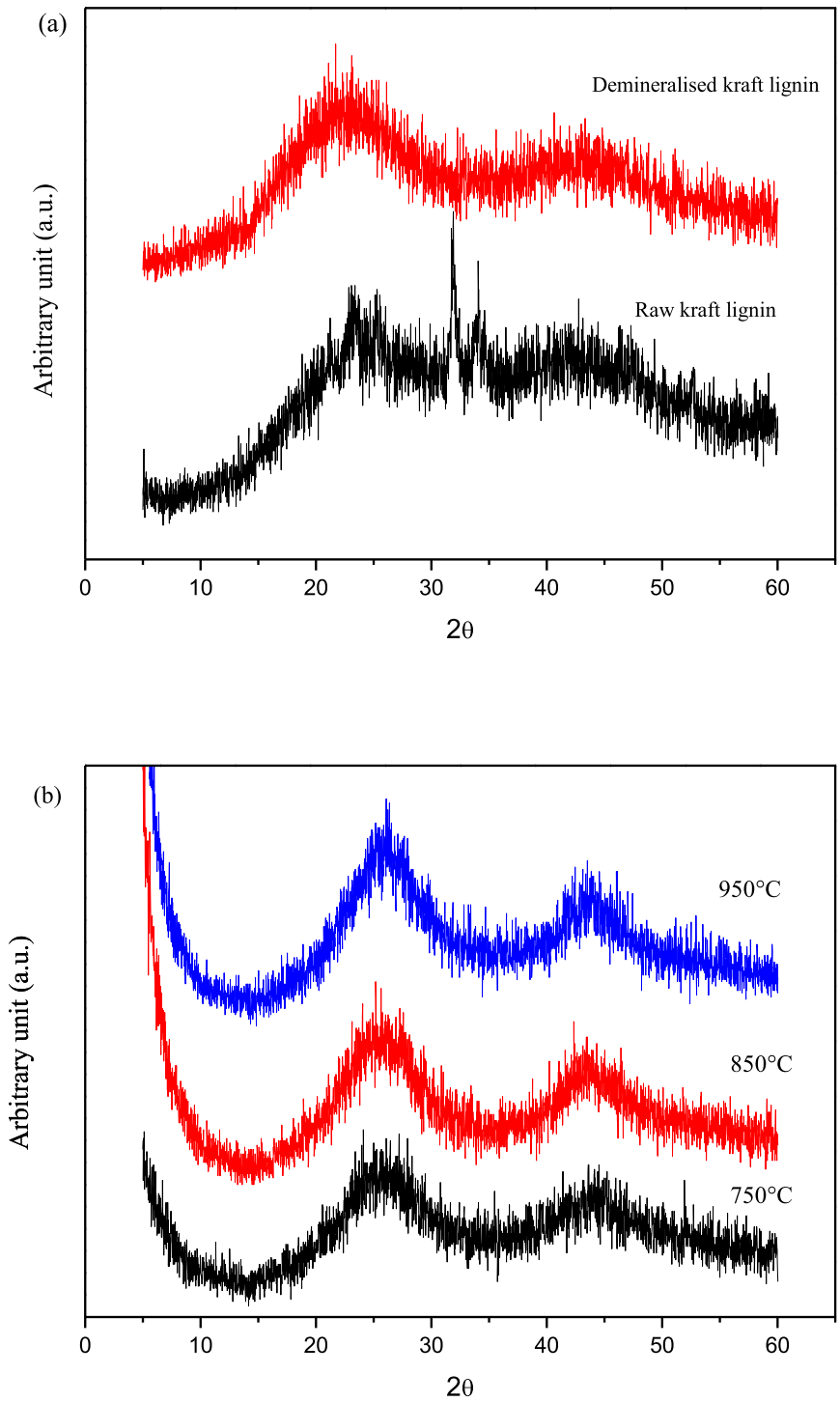

Fig. 1. XRD patterns of (a) raw kraft lignin and demineralised kraft lignin and (b) activated carbons from demineralised kraft lignin at 750,850 and $950{ }^{\circ} \mathrm{C}$.

peaks were observed at $2 \theta 23^{\circ}$ and $43^{\circ}$, corresponding to the (002) and (10) planes, respectively and confirming the formation of typical activated carbons (Madhu et al., 2014; Nabais et al., 2009).

Thermogravimetric analysis is used to have a better understanding about the activation process. The demineralised kraft lignin was submitted to thermogravimetric analysis under nitrogen atmosphere and compared with raw kraft lignin discussed elsewhere (Carrott et al., 2008b). As discussed elsewhere the weight loss in case of demineralised kraft lignin is relatively less than raw kraft lignin especially up to $500{ }^{\circ} \mathrm{C}$ which is an indication of an efficient conversion of lignin in to solid material. Besides this, no sharp loss is observed in the case of demineralised kraft lignin which shows it to be comparatively stable and suggested it can be a choice for a more oxidising atmosphere.

Fig. 2 shows the FTIR spectra of demineralised kraft lignin, the IR bands were assigned according to literature data. A broad band in the range of $3300-3400 \mathrm{~cm}^{-1}$ was found to be associated with the stretching vibration of hydroxyl groups. $\mathrm{C}-\mathrm{H}$ stretching in aromatic methoxyl groups and in methyl and methylene groups of side chains were observed at bands around 2938 and $2842 \mathrm{~cm}^{-1}$. The aromatic ring modes at $1513 \mathrm{~cm}^{-1}$ and $1598 \mathrm{~cm}^{-1}$ and between 1460 and $1470 \mathrm{~cm}^{-1}$ are related to the $\mathrm{C}-\mathrm{H}$ deformation and aromatic ring vibrations, which are considered as the most characteristic infrared bands of lignins. A comparatively more intense band at $1513 \mathrm{~cm}^{-1}$ indicates the lignin sample to be originating from softwood (Sharma et al., 2004). The presence of a peak (CalvoFlores et al., 2015) at $1270 \mathrm{~cm}^{-1}$ was due to guaiacyl units (C-O stretch guaiacyl ring). The bands in the region $1000-1400 \mathrm{~cm}^{-1}$ are as a result of the $\mathrm{C}-\mathrm{O}$ stretching and $\mathrm{OH}$ deformation vibrations, and aryl $\mathrm{CH}$ wags were observed at 856 and $817 \mathrm{~cm}^{-1}$ (Sharma et al., 2004). All the bands observed in the demineralised kraft lignin sample were fairly similar to those observed in raw kraft lignin. However, the difference in the IR spectra was an observation of an intense band at $1721 \mathrm{~cm}^{-1}$ corresponding to $\mathrm{C}=0$ groups not in conjugation with aromatic rings which was similar to that observed by (Fierro et al., 2007b).

The FTIR spectrum of activated carbon from demineralised kraft lignin was also measured and is shown in Fig. 2. It was observed from the figure that the number of bands decreases and that there are also shifts in the positions of the bands remaining after activation (Gao et al., 2013). The hydroxyl group is still present in activated carbon but a reduction is observed in comparison to demineralised kraft lignin (Fu et al., 2013; Nacu et al., 2015). C-H stretching vibrations decreased after activation as did the intensity of the aromatic ring mode which was observed at $1559 \mathrm{~cm}^{-1}$. Moreover, it seems appearance of bands at $1120-1560 \mathrm{~cm}^{-1}$ are due to ether groups (Nacu et al., 2015) formed from decomposition of other groups bands present in the demineralised kraft lignin.

The activated carbon developed was morphologically characterized by FE-SEM and is shown in Fig. 3. Raw kraft lignin particles (images not shown) are usually spherical and non porous and this spherical morphology appears in demineralised kraft lignin samples too, although along with some broken particles and with smooth surfaces. The spherical shape of the demineralised kraft lignin was somewhat preserved even after air activation of samples. A few broken and wide deep structures observed are perhaps due 


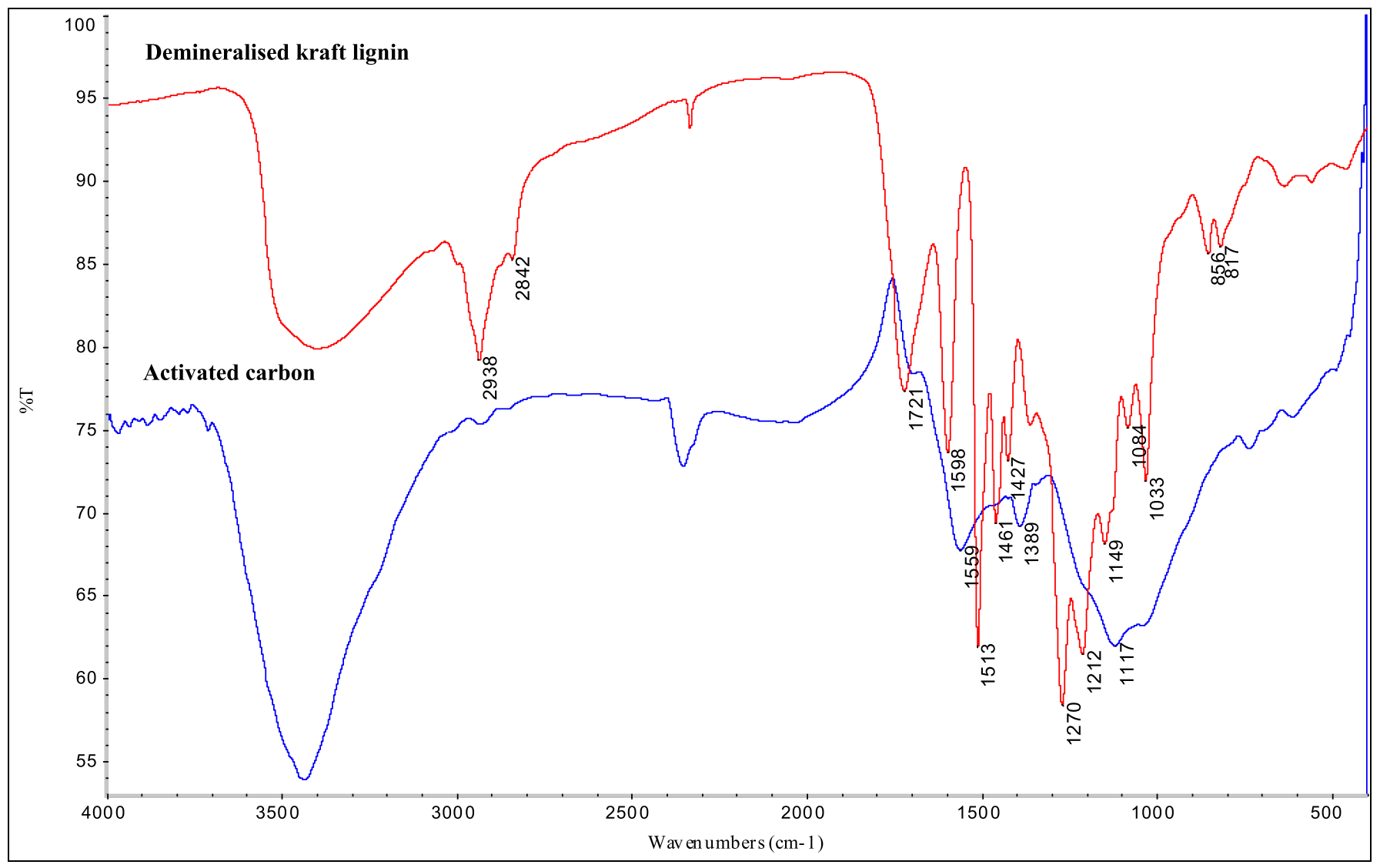

Fig. 2. FTIR spectra of demineralised kraft lignin and activated carbon developed from demineralised kraft lignin at $950{ }^{\circ} \mathrm{C}$.
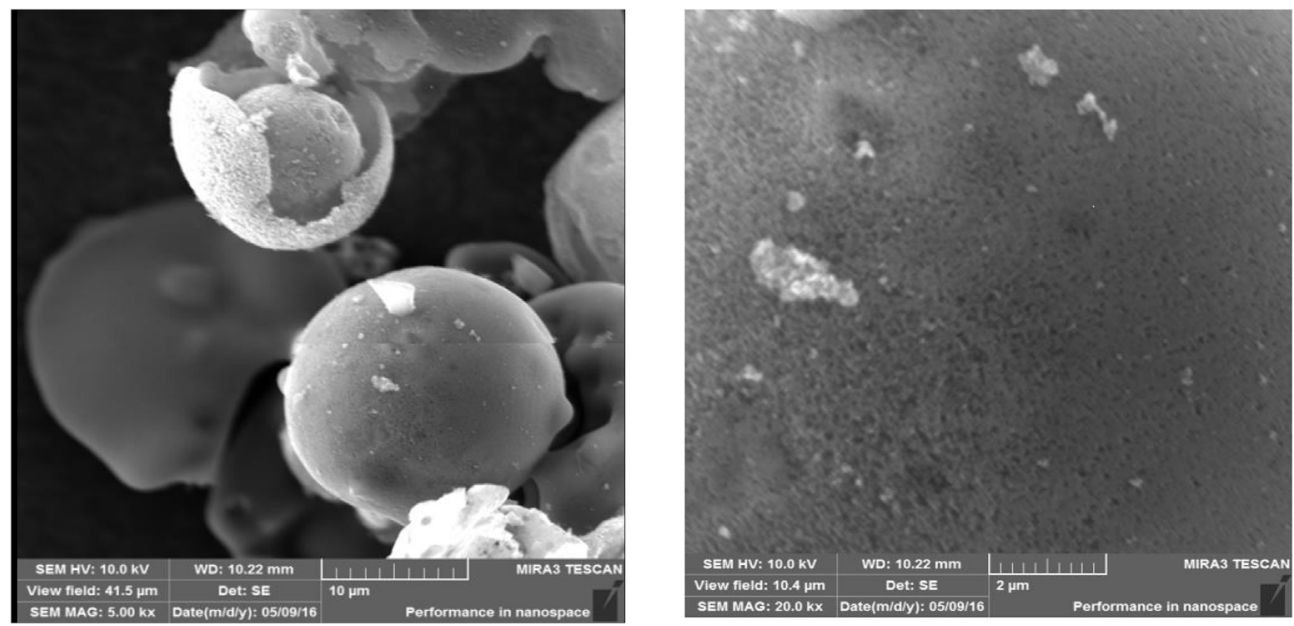

Fig. 3. SEM images of activated carbon developed from demineralised kraft lignin at $950{ }^{\circ} \mathrm{C}$ and different magnifications.

to the highly oxidising atmosphere and burning of the outer part of the particles at high temperature. The activated carbon developed has some irregular surface morphology along with pores and cavities. The inorganic content seems to be quite low which was in good agreement with ash and TGA analysis and is further supported by EDX which was coupled with FE-SEM.

The activation process plays an important role in development of surface area and porosity in materials with temperature being a significant factor in controlling the process. Carbons were prepared at different temperatures and representative $\mathrm{N}_{2}$ adsorption- desorption isotherms of activated carbons prepared from demineralised kraft lignin by air activation in the temperature range $550-1050{ }^{\circ} \mathrm{C}$ at the same heating rate and time are shown in Fig. 4. The figure reveals that the porosity changed with increase of temperature. The isotherms show Type I character in all cases implying that the activated carbon samples were predominantly microporous in nature. However, with increase in the activation temperature, the isotherms became more rounded and for some samples a Type H4 hysteresis loop appeared. Overall the isotherms were fairly similar to those previously obtained with chemically 


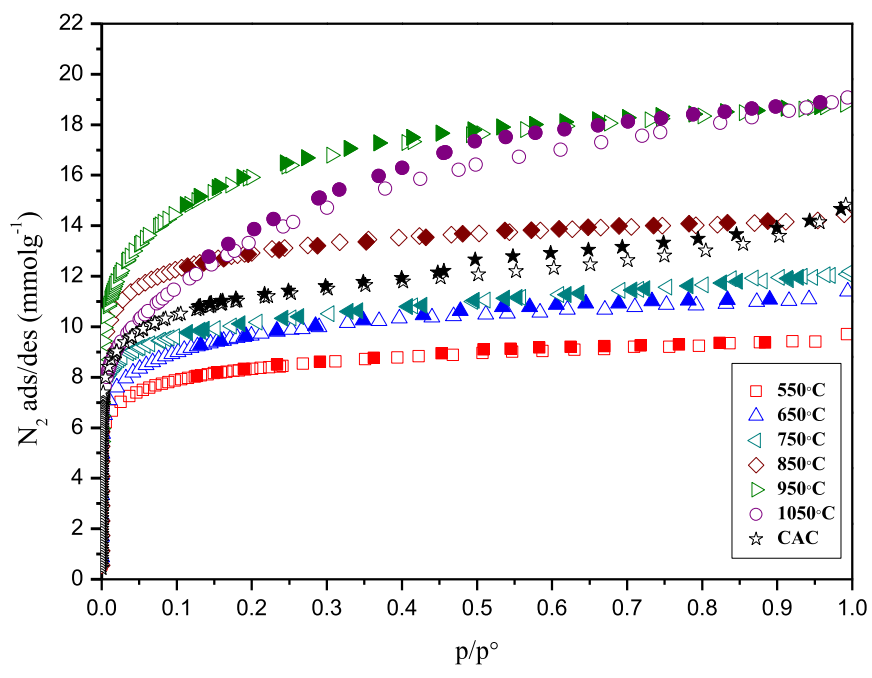

Fig. 4. $\mathrm{N}_{2}$ adsorption-desorption isotherms, at $77 \mathrm{~K}$, determined on air activated demineralised kraft lignins at different temperature and a commercial activated carbon, Open symbols, adsorption; closed symbols, desorption.

activated kraft and hydrolytic lignin as well as to those with physically activated purer hydrolytic lignin at higher temperatures/ burn-off (Carrott et al., 2008b, 2010). The results of the analysis of the isotherms by the BET, $\alpha_{\mathrm{s}}$ and DR methods are given in Table 2 . The carbons prepared at low temperatures had low surface areas and pore volumes. Interestingly, compared to other studies available in the literature at low temperature (Fu et al., 2013; Ozdemir et al., 2014; Shendrik et al., 2007), the activated carbons prepared here from demineralised kraft lignin had much higher surface areas. However, it is particularly notable that the high BET surface areas and total pore volumes were more readily obtained when the activation temperature was $950{ }^{\circ} \mathrm{C}$. The maximum surface area in this work, $1305 \mathrm{~m}^{2} \mathrm{~g}^{-1}$, corresponds to the carbon prepared from demineralised kraft lignin carbon at $950{ }^{\circ} \mathrm{C}$. The surface area observed is quite high for samples prepared in air especially for small activation time $(30 \mathrm{~min})$. The surface area increased with increase of activation temperature up to $950{ }^{\circ} \mathrm{C}$, and decreased with further increase of temperature. It may be due to the fast reactions occurring at higher temperatures which may lead to the widening and destruction of pores and eventually resulting in decrease of surface area (Fu et al., 2013).

In order to compare the surface area, porosity and pore size of the samples prepared, a commercial activated carbon sample was analysed too and the adsorption isotherm is given in Fig. 4. Interestingly demineralised kraft lignin based activated carbon has higher surface area $\left(1305 \mathrm{~m}^{2} \mathrm{~g}^{-1}\right)$ and lower mean pore width $(1.12 \mathrm{~nm})$ than the commercial activated carbon $\left(770 \mathrm{~m}^{2} \mathrm{~g}^{-1}\right.$ and $2.66 \mathrm{~nm}$, respectively), indicating the importance of the samples prepared. Further, it has an economic advantage (Cho et al., 2014) too due to the utilization of air which makes the process less expensive.

The relative contribution of external to the total (or BET) surface area reaches a maximum value close to $10 \%$ at $1050{ }^{\circ} \mathrm{C}$, whereas it is only about $2 \%$ at $850{ }^{\circ} \mathrm{C}$. Table 2 shows that with increase in temperature till $850^{\circ} \mathrm{C}$ up to a mean pore size of about $1 \mathrm{~nm}$, the pore volumes from $\alpha_{s}$ and DR estimates did not show much difference. However, above this temperature and with increase in pore width a bigger difference in the two pore volumes was observed. The mean pore width of the activated carbons from demineralised kraft lignin did not show much appreciable change up to $750{ }^{\circ} \mathrm{C}$ and was predominantly in the ultramicroporous range. Similarly, the characteristic energy $\left(E_{0}\right)$ values were constant too, being inversely proportional to mean pore width (Equation (1)). Table 2 shows that up to $750{ }^{\circ} \mathrm{C}$ the $\mathrm{E}_{\mathrm{o}}$ values are more than $20-22 \mathrm{~kJ} \mathrm{~mol}^{-1}$ indicating the carbons to be homogeneous. However, above this temperature the decreasing $\mathrm{E}_{0}$ values indicate the carbons to be heterogeneous (Rouquerol et al., 1999). However, with increase of the temperature the pore width increased but the samples were still essentially microporous in the working temperature range, which is contrary to the observation made by several workers. For the air activation procedure in this case it may be explained due to the fact that inorganic impurities catalyse the reaction if present whereas their removal can allow us to use a high oxidising atmosphere even with high temperatures.

It can also be seen from Table 2 that pore volumes of activated carbons at different temperatures calculated by the $\alpha_{\mathrm{s}}$ method and the DR method, are obtained in the approximate range of

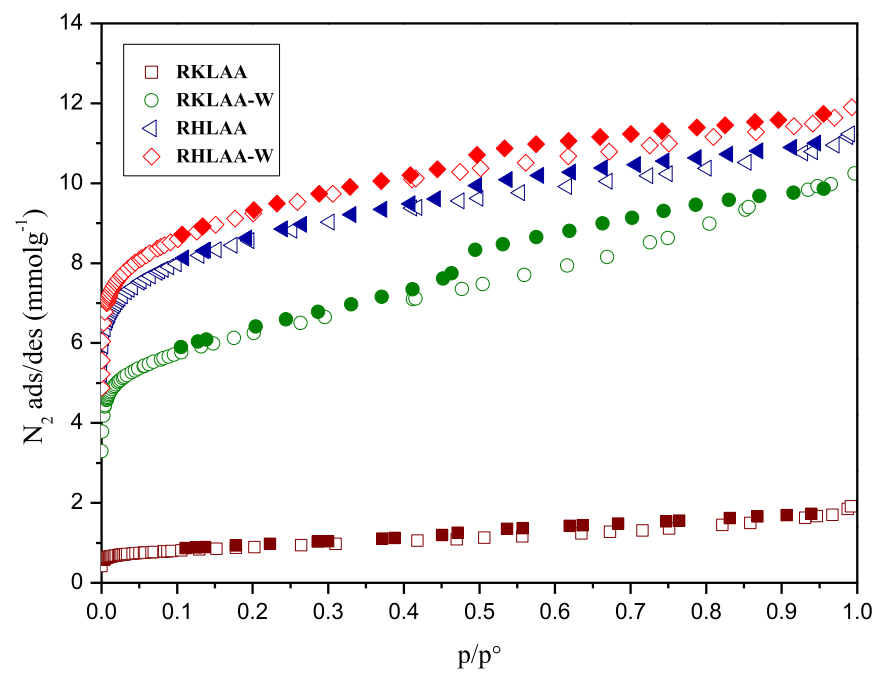

Fig. 5. $\mathrm{N}_{2}$ adsorption-desorption isotherms, at $77 \mathrm{~K}$, determined on raw kraft lignins air activated (RKLAA), raw kraft lignin air activated then washed (RKLAA-W), raw hydrolytic air activated lignin (RHLAA) and raw hydrolytic air activated lignin then washed (RHLAA-W), at $750{ }^{\circ} \mathrm{C}$ temperature, Open symbols, adsorption; closed symbols, desorption.

Table 2

Textural characteristics of the activated carbons obtained from demineralised kraft lignin on activation in the presence of air.

\begin{tabular}{|c|c|c|c|c|c|c|c|}
\hline Rate/Temp/Time & $A_{\text {BET }}\left(m^{2} g^{-1}\right)$ & $A_{s}\left(m^{2} g^{-1}\right)$ & $\mathrm{v}_{\mathrm{s}}\left(\mathrm{cm}^{3} \mathrm{~g}^{-1}\right)$ & $\mathrm{v}_{\mathrm{o}}\left(\mathrm{cm}^{3} \mathrm{~g}^{-1}\right)$ & $\mathrm{L}_{\mathrm{o}}(\mathrm{nm})$ & $\mathrm{E}_{\mathrm{o}}\left(\mathrm{kJ} \mathrm{mol}^{-1}\right)$ & Yield (\%) \\
\hline $8 / 550 / 30$ & 645 & 29 & 0.240 & 0.204 & 0.80 & 24.9 & 31.5 \\
\hline $8 / 650 / 30$ & 715 & 23 & 0.265 & 0.226 & 0.80 & 24.9 & 26.5 \\
\hline $8 / 750 / 30$ & 855 & 29 & 0.313 & 0.267 & 0.80 & 24.8 & 22.5 \\
\hline $8 / 850 / 30$ & 1090 & 22 & 0.388 & 0.344 & 1.05 & 21.7 & 17.1 \\
\hline $8 / 950 / 30$ & 1305 & 78 & 0.472 & 0.374 & 1.12 & 21.0 & 9.1 \\
\hline $8 / 1050 / 30$ & 1044 & 107 & 0.434 & 0.296 & 1.46 & 18.8 & 1.2 \\
\hline
\end{tabular}

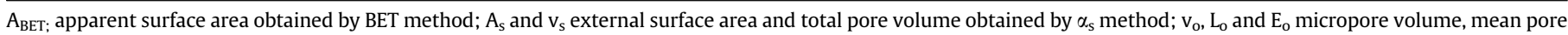
width and characteristic energy obtained by DR method. 
Table 3

Textural characteristics of the activated carbons obtained from raw kraft lignin and hydrolytic lignin on activation in the presence of air.

\begin{tabular}{|c|c|c|c|c|c|c|c|c|}
\hline Precursor & Rate/Temp/Time & $A_{\text {BET }}\left(m^{2} g^{-1}\right)$ & $A_{s}\left(m^{2} g^{-1}\right)$ & $\mathrm{v}_{\mathrm{s}}\left(\mathrm{cm}^{3} \mathrm{~g}^{-1}\right)$ & $\mathrm{v}_{\mathrm{o}}\left(\mathrm{cm}^{3} \mathrm{~g}^{-1}\right)$ & $\mathrm{L}_{\mathrm{o}}(\mathrm{nm})$ & $\mathrm{E}_{\mathrm{o}}\left(\mathrm{kJ} \mathrm{mol}^{-1}\right)$ & Yield (\%) \\
\hline RKLAA & $8 / 750 / 30$ & 70 & 20 & 0.03 & 0.02 & 1.3 & 19.8 & 20 \\
\hline RKLAA-W & $8 / 750 / 30$ & 510 & 84 & 0.19 & 0.16 & 0.84 & 24.3 & 1.9 \\
\hline RHLAA & $8 / 750 / 30$ & 710 & 37 & 0.27 & 0.22 & 0.71 & 26.6 & 8.7 \\
\hline RHLAA-W & $8 / 750 / 30$ & 765 & 35 & 0.29 & 0.23 & 0.72 & 26.3 & 6.7 \\
\hline
\end{tabular}

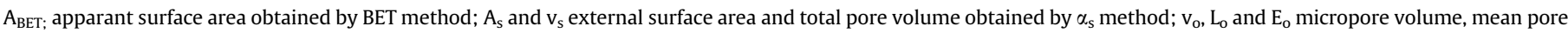
width and characteristic energy obtained by DR method.

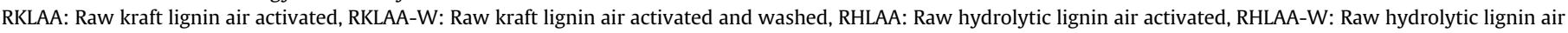
activated and washed.

$0.240-0.472 \mathrm{~cm}^{3} \mathrm{~g}^{-1}$ and $0.204-0.374 \mathrm{~cm}^{3} \mathrm{~g}^{-1}$ respectively. The pore volumes observed are quite high compared to raw kraft lignin activated carbon having inorganic impurities/ash and prepared in $\mathrm{CO}_{2}$ atmosphere (Carrott et al., 2008b) but are comparable to those with $\mathrm{CO}_{2}$ or chemically activated demineralised/low ash kraft lignin samples (Fierro et al., 2007b; Rodriguez-Mirasol et al., 1993). Table 2 also shows that both total pore volume as well as micropore volume increase with temperature and reach a maximum at $950^{\circ} \mathrm{C}$. At temperature higher than $950{ }^{\circ} \mathrm{C}$, there is reduction of the pore volumes due to rapid oxidation, widening and destruction of pores. Interestingly, a comparison of the results obtained by air activation of demineralised kraft lignin with previous studies (Carrott et al., 2008b) with raw kraft lignin in carbon dioxide atmosphere clearly shows the applicability of utilizing air as an activating agent for demineralised kraft lignin. Similar observations were made by (Donald et al., 2011) that demineralisation of the precursor greatly enhances the BET surface area as well as porosity in the AC.

Further, in order to compare the use of air as an activating agent a raw kraft lignin (having ash) and a pure hydrolytic lignin (low ash) were also studied under similar conditions. The $\mathrm{N}_{2}$ adsorptiondesorption isotherms of activated carbons prepared at $750{ }^{\circ} \mathrm{C}$ in air are shown in Fig. 5 and the results given in Table 3. The isotherms present mainly Type I character indicating the carbon samples to be microporous, though with very low surface area and pore volume especially in the case of raw kraft lignin activated in air (designated as RKLAA). However, hydrolytic lignin activated in air (designated as RHLAA) shows appreciable surface areas though lower than demineralised kraft lignin activated in air at the same temperature and also had lower mean micropore width. The low surface area and pore volume observed in the case of air activated raw kraft lignin is due to the fact that raw kraft lignin has high ash content which increases the reactivity (Carrott et al., 2008a, 2008b) leading to collapse of the pores. Besides this the $\mathrm{E}_{0}$ results show

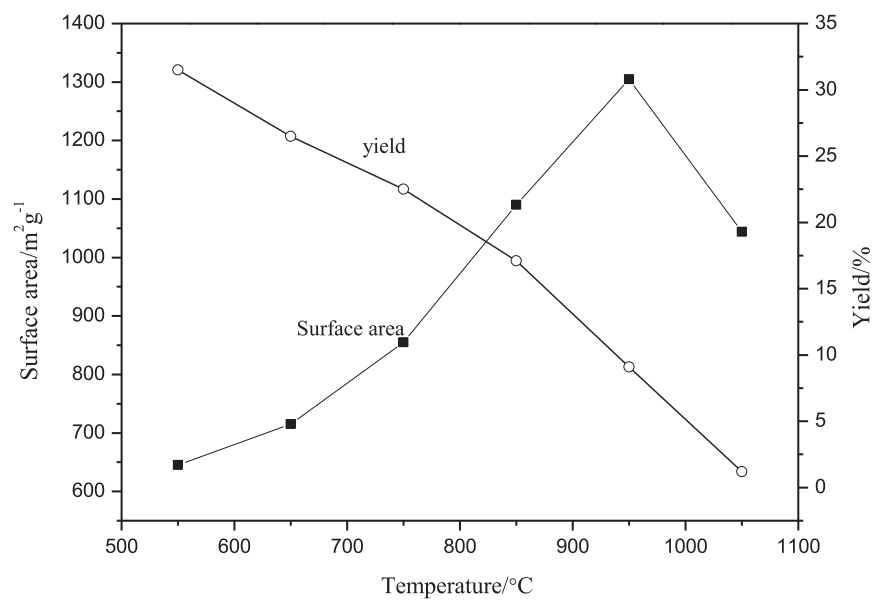

Fig. 6. Variation of surface area $\left(A_{B E T}\right)$ and yield as a function of temperature. that activated carbon from kraft lignin since having low $E_{0}$ value $20-22 \mathrm{~kJ} \mathrm{~mol}^{-1}$ is more heterogenous in nature as compared to other carbons.

Finally, to know whether the ash/mineral content should be removed before or after the preparation of the activated carbon, the activated carbon prepared from raw kraft lignin air activated was washed (designated as RKLAA-W) and the isotherm is presented in Fig. 5 too. An increase in surface area (to $510 \mathrm{~m}^{2} \mathrm{~g}^{-1}$ ) was observed in this case which was presumably due to elimination of impurities A similar study was carried out on raw hydrolytic lignin air activated and washed (RHLAA-W) and a small difference between surface area, pore volume and pore size was also observed, although the difference was less in this case due to the lower ash content. However, in both cases the surface areas and pore volumes were still less than those obtained with demineralised lignin air activated at the same temperature, suggesting that it is preferable to remove the ash before activation.

The amount of product formed (yield) is one of the significant aspects of an activation process. The overall activation yields for the carbon samples prepared from lignin are given in Table 2 and vary between 31.5 and $1.2 \%$. A relationship between activation temperature, surface area and yield is shown in Fig. 6. As expected, the yields decreased more or less linearly with increase of activation temperature, whereas the surface area was found to increase with increase in temperature or decrease in yield and reached a maximum (>1300 $\left.\mathrm{m}^{2} \mathrm{~g}^{-1}\right)$ at $950{ }^{\circ} \mathrm{C}$, with low yields $(9.1 \%)$. However, beyond this temperature $\left(950{ }^{\circ} \mathrm{C}\right)$ the surface area decreased with decrease in yield which is possibly a result of collapsing of the microporous structure and widening of pores. Similar views (Kong et al., 2013) regarding activation yields are available in the literature, namely that the BET surface area increased with increase of temperature and with decrease in yields during the preparation of AC.

The results of yield obtained for demineralised kraft lignin activated carbon were compared with those of raw kraft lignin activated carbon and a pure hydrolytic lignin activated carbon (all prepared under similar conditions and in presence of air at $750{ }^{\circ} \mathrm{C}$ ) and interestingly low yields as well as low surface area were observed for the two, thereby confirming our findings for the parameter yield too.

\section{Conclusions}

In the present work, demineralised kraft lignin was used as a precursor for the preparation of microporous activated carbon by physical activation in an oxidising atmosphere, air. Demineralisation played an important role in preparing the carbons and allowing a highly oxidising atmosphere to be used. Air activation of demineralised kraft lignin allows activated carbon with high BET surface areas up to $1305 \mathrm{~m}^{2} \mathrm{~g}^{-1}$ to be achieved. The activated carbons developed were essentially microporous in nature. A comparison of activated carbons from demineralised kraft lignin with 
activated carbons from other lignin samples prepared under similar conditions showed it to be more porous and of greater surface area. A major achievement of this work is to develop a less expensive as well as high surface area activated carbon from demineralised kraft lignin in the presence of air which is usually difficult to carry out with other precursor materials.

\section{Acknowledgements}

One of the authors (Monika Chaudhary INSPIRE Fellow code IF120368) is grateful to the DST (Department of Science and Technology), New Delhi, India for the award of a doctoral grant (No. DST/INSPIRE Fellowship/2012/346). The authors thank Dr. V. Fierro for providing the lignin sample.

\section{References}

Abbaszadeh, S., Wan Alwi, S.R., Webb, C., Ghasemi, N., Muhamad, I.I., 2016. Treatment of lead-contaminated water using activated carbon adsorbent from locally available papaya peel biowaste. J. Clean. Prod. 118, 210-222.

ASTM, 2004a. Standard Test Method for Total Ash Content of Activated Carbon, ASTM D2866-94. ASTM International, West Conshohocken, PA.

ASTM, 2004b. Standard Test Methods for Moisture in Activated Carbon, ASTM D2867-04. ASTM International, West Conshohocken, PA.

Benaddi, H., Legras, D., Rouzaud, J.N., Beguin, F., 1998. Influence of the atmosphere in the chemical activation of wood by phosphoric acid. Carbon 36, 306-309.

Betancur, M., Bonelli, P.R., Velasquez, J.A., Cukierman, A.L., 2009. Potentiality of lignin from the Kraft pulping process for removal of trace nickel from wastewater: effect of demineralisation. Bioresour. Technol. 100, 1130-1137.

Calvo-Flores, F.G., Dobado, J.A., Isac-García, J., Martín-Martínez, F.J., 2015. Lignin and Lignans as Renewable Raw Materials: Chemistry, Technology and Applications. Wiley.

Carrott, P.J.M., Ribeiro Carrott, M.M.L., Mourão, P.A.M., Guerrero, C., Delgado, L.A., 2008a. Reactivity of cork and lignin for the production of activated carbons Mater. Sci. Forum 587, 618-622.

Carrott, P.J.M., Ribeiro Carrott, M.M.L., Roberts, R.A., 1991. Physical adsorption of gases by microporous carbons. Colloids Surf. 58, 385-400.

Carrott, P.J.M., Ribeiro Carrott, M.M.L., Suhas, 2010. Comparison of the DubininRadushkevich and Quenched Solid Density Functional Theory approaches for the characterisation of narrow microporosity in activated carbons obtained by chemical activation with $\mathrm{KOH}$ or $\mathrm{NaOH}$ of Kraft and hydrolytic lignins. Carbon 48, 4162-4169.

Carrott, P.J.M., Suhas, Ribeiro Carrott, M.M.L., Guerrero, C.I., Delgado, L.A., 2008b. Reactivity and porosity development during pyrolysis and physical activation in $\mathrm{CO}_{2}$ or steam of kraft and hydrolytic lignins. J. Anal. Appl. Pyrolysis 82, 264-271.

Ceyhan, A.A., Sahin, O., Saka, C., Yalçın, A., 2013. A novel thermal process for activated carbon production from the vetch biomass with air at low temperature by two-stage procedure. J. Anal. Appl. Pyrolysis 104, 170-175.

Cho, J.-H., Kim, Y.-S., Jeon, S.-B., Seo, J.-B., Jung, J.-H., Oh, K.-J., 2014. Improvement of thermal regeneration of spent granular activated carbon using air agent: application of sintering and deoxygenation. Korean J. Chem. Eng. 31, 1641-1650.

Cotoruelo, L.M., Marques, M.D., Daz, F.J., Rodriguez-Mirasol, J., Rodriguez, J.J. Cordero, T., 2012. Adsorbent ability of lignin-based activated carbons for the removal of p-nitrophenol from aqueous solutions. Chem. Eng. J. 184, 176-183.

Donald, J., Ohtsuka, Y., Xu, C., 2011. Effects of activation agents and intrinsic minerals on pore development in activated carbons derived from a Canadian peat. Mater: Lett. 65, 744-747.

Fierro, V., Torne-Fernandez, V., Celzard, A., 2006. Kraft lignin as a precursor for microporous activated carbons prepared by impregnation with orthophosphoric acid: synthesis and textural characterisation. Microporous
Mesoporous Mater. 92, 243-250.

Fierro, V., Torne-Fernandez, V. Celzard, A., 2007a. Highly microporous carbons prepared by activation of kraft lignin with $\mathrm{KOH}$. Stud. Surf. Sci. Catal. 160, 607-614.

Fierro, V., Torne-Fernandez, V., Celzard, A., Montane, D., 2007b. Influence of the demineralisation on the chemical activation of Kraft lignin with orthophosphoric acid. J. Hazard. Mater. 149, 126-133.

Fu, K., Yue, Q., Gao, B., Sun, Y., Zhu, L., 2013. Preparation, characterization and application of lignin-based activated carbon from black liquor lignin by steam activation. Chem. Eng. J. 228, 1074-1082.

Gao, Y., Yue, Q., Gao, B., Sun, Y., Wang, W., Li, Q., Wang, Y., 2013. Preparation of high surface area-activated carbon from lignin of papermaking black liquor by $\mathrm{KOH}$ activation for $\mathrm{Ni}(\mathrm{II})$ adsorption. Chem. Eng. J. 217, 345-353.

Gonzalez-Serrano, E., Cordero, T., Rodriguez-Mirasol, J., Cotoruelo, L., Rodriguez, J.J., 2004. Removal of water pollutants with activated carbons prepared from $\mathrm{H}_{3} \mathrm{PO}_{4}$ activation of lignin from kraft black liquors. Water Res. 38, 3043-3050.

ISO, 1997. Solid Mineral Fuels - Determination of Ash Content, ISO 1171:1997. International Organization for Standardization, Geneva, Switzerland.

ISO, 2003. Hard Coal-Determination of Total Moisture, ISO 589:2003. International Organization for Standardization, Geneva, Switzerland.

Kong, J., Yue, Q., Huang, L., Gao, Y., Sun, Y., Gao, B., Li, Q., Wang, Y., 2013. Preparation, characterization and evaluation of adsorptive properties of leather waste based activated carbon via physical and chemical activation. Chem. Eng. J. 221, 62-71.

Kumar, A., Jena, H.M., 2016. Removal of methylene blue and phenol onto prepared activated carbon from Fox nutshell by chemical activation in batch and fixedbed column. J. Clean. Prod. 137, 1246-1259.

Madhu, R., Veeramani, V., Chen, S.-M., 2014. Heteroatom-enriched and renewable banana-stem-derived porous carbon for the electrochemical determination of nitrite in various water samples. Sci. Rep. 4, 1-8.

Nabais, J.M.V., Gomes, J.A., Suhas, Carrott, P.J.M., Laginhas, C., Roman, S., 2009. Phenol removal onto novel activated carbons made from lignocellulosic precursors: influence of surface properties. J. Hazard. Mater. 167, 904-910.

Nacu, G., Negril, L., Rosca, M., Smaranda, C., Bulgariu, L., Gavrilescu, M., 2015. Efficient removal of $\mathrm{Pb}(\mathrm{II})$ ions from accidental polluted waters by adsorption onto thermal activated lignin. In: The 5th IEEE International Conference on E-health and Bioengineering Conference (EHB) 2015, pp. 1-4.

Ozdemir, I., Sahin, M., Orhan, R., Erdem, M., 2014. Preparation and characterization of activated carbon from grape stalk by zinc chloride activation. Fuel Process. Technol. 125, 200-206.

Rodriguez-Mirasol, J., Cordero, T., Rodriguez, J.J., 1993. Preparation and characterization of activated carbons from eucalyptus kraft lignin. Carbon 31, 87-95.

Rosas, J.M., Berenguer, R., Valero-Romero, M.J., Rodriguez-Mirasol, J., Cordero, T., 2014. Preparation of different carbon materials by thermochemical conversion of Lignin. Front. Mater. 1, 1-17.

Rouquerol, F., Rouquerol, J., Sing, K.S.W., 1999. Adsorption by Powders and Porous Solids: Principles, Methodology and Applications. Academic Press, San Diego.

Ruiz-Fernandez, M., Alexandre-Franco, M., Fernandez-Gonzalez, C., GomezSerrano, V., 2011. Development of activated carbon from vine shoots by physical and chemical activation methods. Some insight into activation mechanisms. Adsorption 17, 621-629.

Sharma, R.K., Wooten, J.B., Baliga, V.L., Lin, X., Geoffrey Chan, W., Hajaligol, M.R. 2004. Characterization of chars from pyrolysis of lignin. Fuel 83, 1469-1482.

Shendrik, T., Simonova, V., Kucherenko, V., Pashchenko, L., Khabarova, T., 2007. Adsorption properties of active carbon from lignin. Solid Fuel Chem. 41, 39-44.

Shou, J., Oiu, M., 2016. Adsorption kinetics of phenol in aqueous solution onto activated carbon from wheat straw lignin. Desalin. Water Treat. 57, 3119-3124.

Suhas, Carrott, P.J.M., Ribeiro Carrott, M.M.L., 2007. Lignin - from natural adsorbent to activated carbon: a review. Bioresour. Technol. 98, 2301-2312.

Suhas, Carrott, P.J.M., Ribeiro Carrott, M.M.L., 2009. Using alkali metals to control reactivity and porosity during physical activation of demineralised kraft lignin. Carbon 47, 1012-1017.

Sych, N.V., Trofymenko, S.I., Poddubnaya, O.I., Tsyba, M.M., Sapsay, V.I. Klymchuk, D.O., Puziy, A.M., 2012. Porous structure and surface chemistry of phosphoric acid activated carbon from corncob. Appl. Surf. Sci. 261, 75-82. 